\title{
11. The Kup Women for Peace: A Localized and Innovative Approach to Free, Fair and Peaceful Elections
}

\author{
Rachael Hinton, Michelle Kopi, Angela Apa, Agnes Sil, Mary \\ Kini, Jerry Kai, Yanny Guman and Daniell Cowley
}

Despite the longevity and success of some non-government organizations (NGOs) in Papua New Guinea, civil society is in its early days and is limited in its scope (Pelto 2007). However, in the absence of a strong state, civil society groups that have developed within a context of conflict are responding to issues of violence in their communities. Small-scale, localized interventions that focus on human rights and human security issues and develop their own strategies for violence reduction are seeing positive law and justice outcomes. A strong feature of the 2007 national election in Papua New Guinea was the involvement of civil society and NGO groups working in conflict areas. These groups were seen as instrumental to the drive for a free, fair and peaceful election.

National elections in Papua New Guinea are keenly observed and well documented. The literature of the last decade has provided a thorough examination of electoral processes and systems (Standish 1996, 2002a, 2002b, 2006, 2007; May 2003; Gibbs, Haley and McLeod 2004), the participation of women (McLeod 2002; Sepoe 2002; Kidu and Setae 2002) and the role of elections in contemporary conflict (Weiner, McLeod and Yala 2002; Dinnen 1996). However, as McLeod (2004) asserts, the voices of those attempting to counter problematic trends and processes in Papua New Guinea's electoral politics are given little space to be heard. The following discussion attempts to fill this gap.

This chapter, based on interviews with men and women from Kup communities, examines a unique approach by a community-based organization, Kup Women for Peace (KWP), during the election period in Chimbu Province. KWP developed its own comprehensive and localized strategy, based on their peacebuilding work, and engaged the local community. Their approach sought not only to prevent election-related violence but also improve the electoral process and ensure a free and fair election. KWP applied new and creative practices, which developed outside the normal paradigms utilized by government and official bodies. 


\section{Kup Women for Peace}

KWP is a local non-government organization from Kup, a sub-district of Kerowagi District in Chimbu Province in the Highlands of Papua New Guinea. Kup subdistrict has a population of 24,000, dispersed across many small, isolated communities, many of which are inaccessible by vehicle and lack access to basic services. Although remoteness plays a part, the impact of two decades of tribal warfare in Kup has contributed significantly to a lack of social and economic growth in the area.

The first tribal fight was recorded in Kup in the early 1970s, and although the major fights between tribes ended in 1990, fights between sub-clans continued, motivated in part by election violence (Garap 2004). Kup experienced a downward spiral in social order, laying the foundation for raskol activities, frustration, and limited social and infrastructure development. The court system, the police and other law-enforcement agencies of the central government declined in effectiveness, negatively impacting on livelihoods and contributing to the escalation of violence. The cumulative effects of tribal warfare resulted in social disruption, internal displacement and lack of access to government services, all significantly impacting on the lives of women and children.

KWP was formed in 1999 by women who had experienced the negative impacts of two decades of tribal warfare and who mobilized women from opposing sides to put pressure on traditional leadership to stop the fighting. Now with representation and a strong collective presence throughout the entire subdistrict, the organization has become a powerful force for peace and human rights in local communities. The primary objective of KWP is to reduce conflict and build peace through the cessation of tribal violence. They have had notable success in stopping tribal fighting in the Kup area and in promoting peaceful development. Specific to their work is an emphasis on community empowerment and encouraging men and women to take control of their own development in the absence of government support and infrastructure.

KWP takes a collective and human rights-based approach to reinforce peace. Through capacity building and training, the aim is to increase respect and awareness of human rights and reduce gender violence. Restorative justice processes and partnerships are integral to their approach, as well as providing young men in particular with productive alternatives to crime. KWP mediate disputes to prevent outbreaks of tribal fighting and engage with groups across the conflict divide. They negotiate for communities to receive basic social services (such as health, water supply, education and police), and these are used to reinforce community unity and peace. KWP is also committed to strengthening their organizational capacity with a view to delivering more 
responsive training and improved peace facilitation. KWP receives widespread support throughout the sub-district and there is a realization that the relatively peaceful situation in Kup now needs to be consolidated through the further provision and strengthening of basic services and development initiatives.

Election-related violence was widespread during the 2007 election in Chimbu Province, resulting in multiple deaths (The National 8 August 2007), destruction of houses, displacement of communities (The National 8, 31 August 2007), and women prohibited from accessing basic maternal health services (The National 13, 25 July 2007). Some high-powered weapons were seized (Post-Courier 6 July 2007; The National 13, 25 July 2007) but guns were used during election-related tribal clashes (Post-Courier 20 July 2007; The National 21 August 2007). Kup sub-district, however, presents a unique case for consideration. This rural community, widely known for its large-scale conflict and tribal violence, has been displaying a significant improvement in law and order due to the work of KWP. The success of the group's work in communities was particularly evident during the recent election in Kup. This case study provides an insight into the dynamics of a grassroots organization working to improve election practices and processes and sustain peace in communities where governmental processes have proved insufficient.

\section{Previous election experiences in Kup}

Election-related violence and flawed democratic processes were prevalent in Chimbu Province during past elections (Standish 1989, 1996; Dika 2003). For example, during the 1997 election two candidates and their supporters in Kundiawa threatened voters with high-powered weapons during polling and counting. In Sinasina, ballot papers were stolen and sold for K1.00 each, after the presiding officer was forced to sign them. In another example, a candidate (a former police officer) allegedly arranged the kidnapping of another candidate's supporter and demanded that they withdraw from the contest. The escalation of violence resulted in the deterioration of basic services, the destruction of property and restrictions on movement (Dika 2003).

Violence between supporters in Kup erupted during the 1997 and 2002 elections, mainly related to vote-splitting, inconsistent support for a candidate, restrictions on campaigning, bloc voting, and ballot papers being stolen or destroyed. It was rare for women to vote, as a result of men voting on their behalf or women feeling too afraid or intimidated. There was a strong presence of guns and limited freedom to cast a vote of choice. As a KWP member recalled, 'There is always lots of pushing and shoving. And people bring guns to the voting stations so we feel afraid to go and vote under the threat of a gun'. A large police 
contingent was always present in preparation for outbreaks of violence. KWP were determined to prevent similar violence from erupting over what was seen as a short and unsustainable period of 'election fever', which would inevitably reverse the results of their 'hard work'.

\section{Pre-election activities}

As with past elections, the 2007 national election was assessed for its security threat and potential to fuel violence, particularly in areas of the Highlands Region marked by serious outbreaks of inter-group conflict (Post-Courier 10 May, 26 June, 10 July 2007; The National 11 May 2007). In contrast to the national media discussion, which focused on the 'peaceful' component of the Electoral Commission's campaign, KWP took practical steps to ensure the validity of the electoral process and in turn create conditions for peace. Their aim was not simply to police the elections but to ensure a fair and free process. Working in a context of long-term conflict, KWP are well aware of the danger of prioritizing a well-policed election to the neglect of a legitimate and valid electoral process.

KWP decided on a three-pronged strategy: cohesive voter education, the launching of the Livelihoods Programme, and a Violence-Free Election campaign. Program and in-kind assistance was used to support these activities, with no specific funding support from the Electoral Support Program. Voter education was conducted over a two week period, throughout the entire Kup sub-district, and covered issues including limited preferential voting (LPV), the purpose and process of the election, voters' rights, choice and definition of a good leader, and the purpose of political representation. KWP received positive feedback from their outreach activities and men and women made clear the type of leaders they wanted, such as a person who was committed to their community and moved beyond their own self-interest.

Although candidates distributed cash throughout the sub-district, community members were resistant to vote-buying; as a KWP member claimed:

Ol i no save tingim mipela, na ol $i$ save go bildim "own castle" bilong ol, na ol save paulim mipela wantaim K10 or K50 long poket bilong mipela na mipela save strong long sapotim ol! Tasol nau nogat

(They don't remember us and they go and build their own castle and they simply confuse us with K10, K50 to fill our pockets and for that we support them! But not any more).

During voter awareness it became clear, however, that there was much confusion about the LPV system and about how preferences could be used. KWP members 
believe this was related to the delayed and rushed national electoral awareness campaign. Had the campaign been initiated earlier, undertaken over a longer period, and completed well ahead of the campaign period, understanding of LPV processes may have been dramatically improved. As a result, LPV awareness received specific attention during KWP voter education activities. Booklets were also delivered to campaign houses for candidates to discuss with people during the evenings. The KWP HIV coordinator also conducted awareness in campaign houses during the campaign period.

The second component targeted youth as part of KWP's Sustainable Livelihoods Programme. Fifty-four youth groups received project materials, including goats, rabbits, chickens, pigs, cement bags, and pipes for fish ponds, and the project was expected to directly benefit 3000 to 4000 people. Some of the youth had been part of a 2003 gun surrender organized by KWP yet were perceived to still have the potential to instigate violence. KWP's intention in targeting youth was to 'settle the youth down and keep them busy' to reduce the propensity for election-related violence. By committing themselves to livelihood activities, the hope was that the youth would become responsible for their own development and wellbeing.

The third component was more direct in its targeting of intending candidates. In conjunction with the launching of the Livelihoods Programme, KWP advocated a Violence-Free Election 2007. The rationale for combining the two occasions was that young men often take the lead to fuel violence during political campaigns, supported by political candidates. The candidates, who thought they were attending the Livelihoods Programme launching, were asked to commit themselves to a violence-free election and sign an agreement in public. Of the 14 candidates invited, 11 attended and all gave assurances to the community that they would support a violence-free and gun-free election, and not encourage young men to fight. Of the three that did not attend, one shot and killed a man in Kup during an election-related dispute, and a second attempted to intimidate polling officials prior to the ballot papers being distributed to polling booths in Kup Station.

\section{Polling day: 9 July 2007}

The KWP response to illegitimate electoral practices and the threat of election-related violence on the day of polling was marked by innovation and adaptability. KWP understood the context and what was necessary to ensure a valid political process and fair outcome in the sub-district. KWP sometimes 
took an unconventional approach, but the group saw their actions as completely justified and necessary given the experiences of past elections in the area. Two examples are provided below.

Several KWP members had received training from the Electoral Commission to work as polling officials in their area. When a member was organizing her ballot boxes and materials for delivery to Kup she became aware of three candidates driving with their supporters in what she perceived to be an attempt to hijack the ballot papers on route to Kup. In response, she waved down a passing car and the local leader inside agreed to take a message to the Kerowagi District Office to ensure an alternative road or transport was used. As she said: 'I stood in the middle of the road to stop the car, I had no choice. They could have had guns'. As a result of her intervention, the papers were delivered by helicopter to Kup.

Secondly, a large crowd had gathered to witness the ballot papers being delivered. The returning officer and presiding officer stepped from the helicopter, carrying a small bag and a large briefcase respectively. Because of the size of his bag, the crowd assumed the presiding officer had the papers and proceeded to follow him, while at the suggestion of two KWP members the smaller bag containing the ballot papers was taken by the returning officer and the police officer and kept in the care of the two KWP members for the entire evening. The story continues:

At night everyone was hunting the presiding officer down. One man came and brought his gun and was making accusations that people wanted to sign the ballot papers. The presiding officer told everyone to leave him alone as he had the ballot papers and he didn't want to fail in his duty. No one in the area where the presiding officer was staying or surrounding villages slept during the night. They were alert and awake and provided security for the ballot papers until dawn. We were relaxing! They wanted to take the police officer who was with us as well but we said it was late, and he needs to rest as the only one supervising the elections tomorrow. The presiding officer came to the centre with his briefcase the following morning. We fell about laughing on the grass. We couldn't stop laughing. The presiding officer said, 'all this time they think I have been carrying the ballot papers. I am such an actor! It was hard work!'

An unconventional approach was seen as the only alternative to prevent the ballot papers being stolen as was usual practice in past elections. KWP feel strongly that their actions assured people of the right and opportunity to make their own voting choices. As a KWP member said, 'Who knows what other people would have done if they got the papers but we know that we looked 
after them, they were protected by us'. Further, when sorting the ballot papers according to ballot stations, a Kup candidate wearing a long coat (which could have concealed something), attempted to intimidate the KWP members and the presiding officer to reduce the number of voting stations in the Kup Station area from three to one. They refused to give in to his demands, reinforcing the need to follow due process. They gained strength from the fact that they too were from Kup, with their own support network. 'What could he do to us?', one of the KWP members present at the time asked.

With the assistance of polling officials and one police officer for the entire subdistrict, KWP set up the polling booths and controlled the voting process. This included enforcing separate lines for men and women, the equal representation of male and female voters, and privacy to vote. Knowledge and understanding of the area was paramount, such as what clans were present, or who had to be watched as a security threat. If a man voted, a woman would follow. Tally sheets were crucial in ensuring due process and a balanced gender representation. If the tally sheets showed men were five ahead, five women were called to vote. KWP members were clear and forthright about the process that was to be followed, and open communication was seen as fundamental to the outcome. If some of the young men started to push or attempted to vote twice they were reprimanded, and in some cases voting was suspended until the issue was resolved. Again, being from the area was regarded as safety net, 'I am from here too, so what can they do?' ('Ol as ples, mi as ples tu, bai ol wokim wanem?'), a female KWP member said.

However, the capacity to control the voting process went beyond KWP members simply being from the area. Respect was shown by the community to KWP members throughout the election period, especially the women who were founding members and had shown their commitment to peace-work in their communities. 'Ol mama wok na larim ol wokim long wanem we ol laikim' ('It is our mothers controlling it [the voting] so let them do it the way they want to'), was a comment regularly heard. As one of the KWP members commented:

For us, over the years we have been working we have seen a marked difference in our community. We have respect and when we ran the election they respected us, we gave education, we told them about changes in the law so they heard it and came to vote peacefully. Towards the end they wanted to rush to get the papers but we told them that they couldn't ruin it, we had done so well to that point.

Discrepancies in the common roll and insufficient numbers of ballot papers assigned to the voting population were common problems throughout the Kup sub-district. Dissatisfaction was expressed by those who did not vote, as they saw it as a chance missed to participate in an election that was well controlled, 
fair and open to all. Satisfied, however, with what was seen as a legitimate and locally controlled voting process, everyone clapped as the last ballot paper was signed, and voters as well as candidates and scrutineers dispersed. The ballot boxes were locked and, unlike previous elections, left unguarded until the Defence Force arrived to pick up the boxes late in the afternoon.

\section{A local response to local issues}

KWP utilized their extensive network, built on widespread voter education and the launching of the Violence-Free Election campaign, to create an alternative election practice. KWP members and KWP community police were present at every voting station and it was the responsibility of KWP members who were working everyday on the ground to be alert and respond to problems in their community as they arose. Not one of the candidates who signed the agreement with KWP was involved in any election-related problems, and voter education combined with the Livelihoods Programme was seen as critical to keeping candidates from stimulating or sustaining conflict. Not one tribal fight occurred in Kup during or following the election period. No guns were present during voting and any pressure by young men to persuade voters to choose a specific candidate was immediately condemned. No ballot papers were stolen or signed prior to or following polling. There was a marked improvement in the representation of women. Female voters were excited by the opportunity to vote, as the following comment by a female community member highlights: 'Every election, I have had candidates I liked but I couldn't vote for them, now I voted for who I wanted'.

Much is being said in Chimbu about the non-violent election in Kup, compared with other parts of Chimbu where election-related violence was widespread. As one male community member noted, 'In Simbu people think that, em nau, taim bilong eleksin na bai mipela lukim namba wan paia long Kup na ol bai kukim haus bikos ol save mekim olsem long ol yia i kam so ol bai wokim' ('it's election time, we will see the first fire burning in Kup, they will set houses alight because that is what has always happened in the previous elections'). It was ironic that KWP community police were 'camping out' in Kerowagi in an attempt to prevent a tribal fight from erupting in response to an election-related death. Unlike previous years, only one police officer was delegated to the entire Kup subdistrict on the day of polling.

The pride and confidence shown by KWP members for the part they played in ensuring a violence-free and fair election is immeasurable. Their success is seen as a 'dream come true' and the 'first of its kind in Kup history'. KWP is a women's organization that has broken the barrier of male dominance, and men 
are showing respect for and confidence in the members of the organization and their activities. After many years of hard work 'sweating, talking, sleeping out, lighting lamps to walk in the dark, in the rain', and in the face of some criticism by community members for the lack of practical change in communities, KWP believe the result is indisputable. KWP members welcome the opportunity to oversee the 2012 elections in Kup.

This is not to say there were no election-related problems in Kup. Campaign houses, for example, were identified as a cause of conflict prior to polling, a drain on resources for both supporters and candidates, and, due to the increased movement of men and women at night, a determinant of domestic violence, unwanted pregnancies, rape and the spread of HIV. The role of campaign houses in Kup during the 2012 elections is being seriously questioned by some KWP members. Also, three men were shot by a candidate in Kup, one of whom died. The community reacted positively to the incident and requests were made to KWP to intervene and mediate the conflict. There is widespread recognition of the peace-building work of KWP throughout the sub-district and with it a realization that KWP can be depended on to support and assist with conflict resolution. KWP members accompanied the victims to hospital and liaised with police over the matter. Due to KWP's mediation and associated activities, the community was able to remain fairly peaceful, when in the past such an incident would have erupted into tribal violence.

Three of the four executive members of KWP had immediate family standing for election. Differing political preferences have proven to be a divisive factor in Papua New Guinea politics and a contributor to disputes and intra- and inter-clan conflict. However, the KWP executive continued their commitment to peace-building throughout the election period. Open communication and respect for individual preferences also helped to negate political divisions and the organization remained united and strong. Inherent in their work is an understanding that despite some differences KWP members must be unified in their approach and provide a positive role model for the community.

\section{Lessons to be learned}

The peace-building activities of KWP over the seven years to 2007, combined with widespread voter education, the Livelihoods Programme and the ViolenceFree Election campaign, had a twofold effect. First, corrupt election practices were strongly rejected in favour of a legitimate and fair process. Secondly, by targeting what have in past elections been the underlying causes of conflict, there was a reduction in election-related disputes and violence. KWP applied practical measures to ensure a valid electoral process and in turn create conditions 
for peace. The two aspects are self-supporting. This must be recognized if we are to see a transformation in political trends and national approaches to electoral processes in Papua New Guinea.

Voter education was more than awareness at a marketplace or displaying posters. Being from the community meant KWP members immersed themselves at the grassroots level, eating and sleeping with the community and talking over the issues at night. KWP feel strongly that people are less responsive to awareness in towns or at the market as people are there to conduct their own business. Complex political concepts such as LPV and voters' rights require time for discussion and clarification. In contrast, KWP believes the messages conveyed during their voter awareness were adopted and well understood by many members of the community in Kup. A KWP member clarified this point:

You have to walk inside, where cars can't go, and sleep in the haus man and talk to them in their house. We sleep in the community and at night we talk; next day we go to another place and from this we have seen success. Money doesn't matter. We slept, got up, ate with the community. We work in a localized way but we see big achievements.

The system of LPV voting was seen as exclusive and a potential source of conflict. It lacked simplicity, English was prioritized over a Tokpisin translation and even when an illiterate voter asserted his/her choice, there was still ample opportunity for those assisting the voter to mark the ballot for their own candidate.

Throughout many parts of Papua New Guinea, polling officials working in their own communities were ineffective and unable to prevent illegitimate and unfair election practices from occurring. Much can be learned from the activities of KWP during the election period. The significance of engaging the local community and political candidates, combined with the influence of a strong and well-respected local organization, resulted in a non-violent election and an impressive improvement in voting rights, practices and processes. Despite this, the negative influence of a flawed common roll had the potential to undermine much of the positive work of KWP. The process of drawing up the roll, which is out of the hands of groups working on the ground, remains a serious potential trigger for conflict in future elections.

\section{Conclusion}

This chapter provides a snapshot of KWP's unique role in the 2007 national election and offers insights and lessons for reducing opportunities for violence. An organic women's organization, in partnership with the community, took 
ownership of the electoral process to ensure a free and largely non-violent election period. The underlying determinants of electoral conflict were targeted in an attempt to create a legitimate process and to reduce the likelihood of election-related disputes. The strategy of voter education, launching the Livelihoods Programme and the Violence-Free Election campaign were localized responses. The 'gunpoint democracy' of past elections (Standish 1996; Gibbs 2004) was rejected and individual rights and values promoted in its place.

The success of KWP lay in its tailored and holistic approach and the attention that was given to issues that were contextually relevant and locally determined. Rather than a 'one size fits all' response, KWP identified overlooked problems and gaps, such as the poor representation of female voters, and developed their own solutions. A homegrown organization, KWP had the capacity to facilitate dialogue with those who were beyond the reach of government. Their responses to potential security threats were often spontaneous, unconventional and improvised but their capacity and confidence to respond lay in their commitment to free not only their own lives but also those of their families and communities from the devastating effects of conflict. KWP's ownership of the election process was an attempt to challenge dominant and detrimental trends in current Papua New Guinea politics.

It is encouraging that a grassroots organization could identify and implement innovative and appropriate strategies and as part of their peace-building activities create an environment in which corrupt electoral practices, violence and discrimination had little weight. Community-based approaches offer alternative options and fresh perspectives to addressing community-based issues such as poor governance, undemocratic electoral processes, and the disenfranchisement of women. The challenge is to ensure that these approaches are recognized, encouraged and supported by national and donor agencies.

\section{References}

Dika, E., 2003. 'The 2002 national election in Chimbu Province', Catalyst 33(1):41-47.

Dinnen, S., 1996. 'Violence, security and the 1992 election', in Y. Saffu (ed.), The 1992 Papua New Guinea Election: Change and Continuity in Electoral Politics. Canberra: Department of Political and Social Change, Research School of Pacific and Asian Studies, The Australian National University, pp. 77-104. 
Garap, S., 2004. 'Kup Women for Peace: women taking action to build peace and influence community decision-making'. State, Society and Governance in Melanesia Discussion Paper 2004/4. Canberra: State, Society and Governance in Melanesia Project, The Australian National University.

Gibbs, P., 2004. 'Democracy and Enga political culture', in P. Gibbs, N. Haley and A. McLeod, 'Politicking and voting in the highlands: the 2002 Papua New Guinea national elections'. State, Society and Governance in Melanesia Discussion Paper 2004/1. Canberra: State, Society and Governance in Melanesia Project, The Australian National University, pp. 2-15.

Gibbs, P., Haley, N. and McLeod, A., 2004. 'Politicking and voting in the highlands: the 2002 Papua New Guinea national elections'. State, Society and Governance in Melanesia Discussion Paper 2004/1. Canberra: State, Society and Governance in Melanesia Project, The Australian National University.

Kidu, C. and Setae, S., 2002. 'Wining and losing in politics: key issues in Papua New Guinea', Development Bulletin 59:51-53.

May, R. J., 2003. 'Disorderly democracy: political turbulence and institutional reform in Papua New Guinea'. State, Society and Governance in MelanesiaDiscussion Paper 2003/03. Canberra: State, Society and Governance in Melanesia Project, Research School of Pacific and Asian Studies, The Australian National University.

McLeod, A., 2002. 'Where are the women in Simbu politics?', Development Bulletin 59:43-46.

McLeod, A., 2004. 'White Horse 27: the electoral campaign of Bari Palma', in P. Gibbs, N. Haley and A. McLeod, 'Politicking and voting in the highlands: the 2002 Papua New Guinea elections'. State, Society and Governance in Melanesia Discussion Paper 2004/1. Canberra: State, Society and Governance in Melanesia Project, The Australian National University, pp. 27-40.

Pelto, M., 2007. 'Civil society and the National Integrity System in Papua New Guinea', Pacific Economic Bulletin 22(1):54-69.

Sepoe, O., 2002. 'To make a difference: realities of women's participation in Papua New Guinea politics', Development Bulletin 59:39-42.

Standish, B., 1989. 'After the big one: the 1982 Chimbu provincial campaign', in P. King (ed.), Pangu Returns to Power: The 1982 Elections in Papua New Guinea. Canberra: Department of Political and Social Change, Research School of Pacific and Asian Studies: The Australian National University. 
Standish, B., 1996. 'Elections in Simbu: towards gunpoint democracy?', in Y. Saffu (ed.), The 1992 Papua New Guinea Election: Change and Continuity in Electoral Politics. Canberra: Department of Political and Social Change, Research School of Pacific and Asian Studies: The Australian National University, pp. 277-322.

Standish, B., 2002a. 'Papua New Guinea politics: attempting to engineer the future', Development Bulletin 60:28-32.

Standish, B., 2002b. 'Electoral governance in Papua New Guinea: Chimbu poll diary, June 2002'. http://exkiap.net/articles/miscellaneous/bill_ standish_20020628. htm\#Bill Standish

Standish, B., 2006. 'Limited preferential voting in Papua New Guinea: some early lessons', Pacific Economic Bulletin 21(1):195-211.

Standish, B., 2007. 'The dynamics of Papua New Guinea's democracy: an essay', Pacific Economic Bulletin 22(1):135-157.

Weiner, J., McLeod, A. and Yala, C., 2002. 'Aspects of conflict in the contemporary Papua New Guinea highlands'. State, Society and Governance in Melanesia Discussion Paper 2002/4. Canberra: State, Society and Governance in Melanesia Project, The Australian National University. 